\title{
Discriminação fonêmica, processamento auditivo e reflexo acústico em crianças com desenvolvimento de fala normal e desviante
}

\author{
Tiago Mendonça Attoni ${ }^{1}$
}

Attoni TM. Discriminação fonêmica, processamento auditivo e reflexo acústico em crianças com desenvolvimento de fala normal e desviante [dissertação]. Santa Maria (RS): Universidade Federal de Santa Maria; 2009.

Este estudo teve por objetivo avaliar a capacidade de discriminação fonêmica, as habilidades do processamento auditivo e os limiares do reflexo acústico em crianças com desenvolvimento fonológico normal e desviante, além disso, também foi analisada a possibilidade de associação entre as três vertentes avaliadas. A amostra foi composta por quarenta e seis crianças, sendo vinte e quatro com desenvolvimento de fala normal e vinte e duas com desenvolvimento de fala desviante, com idades compreendidas entre cinco anos e sete anos e quatro meses. Foram estabelecidos dois grupos, um grupo com crianças portadoras de desvio fonológico e outro grupo com crianças sem desvio fonológico. Para as avaliações foram adotados os mesmos procedimentos de aplicação para os dois grupos. Na avaliação de discriminação fonêmica foi utilizado o Teste de Figuras para Discriminação Fonêmica. Para as avaliações do processamento auditivo foram utilizados a Avaliação Simplificada do Processamento Auditivo, o Teste Pediátrico de Inteligibilidade de Fala (PSI), o Teste
Fala com Ruído, o Teste de Dissílabos Alternados (SSW) e o Teste Dicótico de Dígitos. Os limiares do reflexo acústico foram mensurados por imitanciômetro AZ7 nas frequências de 500,1000, 2000 e $4000 \mathrm{~Hz}$. O tratamento estatístico foi aplicado com o auxílio do programa SAS user's guide: statistical, Analysis System Institute, Inc., Cary, NC, 2001; utilizando o teste de correlação de coeficientes de Pearson, considerandose $\mathrm{p}<0,05$. Os resultados indicaram que crianças com desvio fonológico apresentam déficits na capacidade de discriminação fonêmica, alterações consideráveis em habilidades do processamento auditivo e reflexos acústicos fora dos padrões de normalidade (indicativo para alteração retrococlear, em nível de tronco encefálico). As crianças com desenvolvimento de fala normal obtiveram valores normais em todas as avaliações que foram ministradas. Conclui-se que alterações na discriminação fonêmica, no processamento auditivo e reflexo acústico estão associados ao desvio fonológico. É possível que estes possam influenciar no aparecimento dos desvios de fala.

Trabalho apresentado à Universidade Federal de Santa Maria - UFSM Santa Maria (RS), Brasil, para obtenção do título de mestre em Distúrbios da Comunicação Humana, sob orientação da Profa. Dra. Helena Bolli Mota. (1) Mestre em Fonoaudiologia pela Universidade Federal de Santa Maria UFSM - Santa Maria (RS), Brasil.

Endereço para correspondência: Tiago Mendonça Attoni. R. Cambe, 900, Coqueiros, Belo Horizonte (MG), Brasil, CEP: 30880-440. E-mail: tiagoattoni@yahoo.com.br 